\title{
Wolfgang Reinhard, Die Unterwerfung der Welt. Globalgeschichte der europäischen Expansion, 1415-2015
}

\section{Claire Gantet}

\section{OpenEdition}

\section{Journals}

Édition électronique

URL : http://journals.openedition.org/ifha/8999

DOI : 10.4000/ifha.8999

ISSN : 2198-8943

Éditeur

IFRA - Institut franco-allemand (sciences historiques et sociales)

Référence électronique

Claire Gantet, «Wolfgang Reinhard, Die Unterwerfung der Welt. Globalgeschichte der europäischen Expansion, 1415-2015 », Revue de l'IFHA [En ligne], Date de recension, mis en ligne le 15 mars 2018, consulté le 24 septembre 2020. URL : http://journals.openedition.org/ifha/8999 ; DOI : https://doi.org/ 10.4000/ifha.8999

Ce document a été généré automatiquement le 24 septembre 2020.

(C)IFHA 
Wolfgang Reinhard, Die

Unterwerfung der Welt.

Globalgeschichte der europäischen

Expansion, 1415-2015

Claire Gantet

\section{RÉFÉRENCE}

Wolfgang Reinhard, Die Unterwerfung der Welt. Globalgeschichte der europäischen Expansion, 1415-2015, München: Beck, 2015, 1648 p., $58 €$ 
Entre 1988 et 2009, Wolfgang Reinhard publiait une Histoire de l'expansion européenne (Geschichte der europäischen Expansion) en quatre volumes (Stuttgart, Kohlhammer). Son nouvel ouvrage, paru en 2015, est plus qu'une actualisation bibliographique et une condensation en un volume monumental. Il repose non seulement sur une gigantesque documentation (la liste des sources et de la littérature secondaire couvre 293 pages !), mais aussi une relecture au $\mathrm{vu}$ des interrogations actuelles sur l'histoire globale, sur les relations transculturelles et sur la nécessité d'une décentralisation de l'historiographie.

L'Europe est au cœur de l'histoire, mais non en son centre, et l'Europe n'est pas une entité figée. Bien plus, l'Europe est, d'emblée et jusqu'à aujourd'hui, marquée

WOLFGANG REINHARD

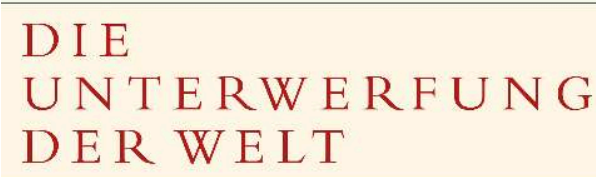

GLOBALGESCHICHTE DER

EUROPÄISCHEN EXPANSION 1415-2015

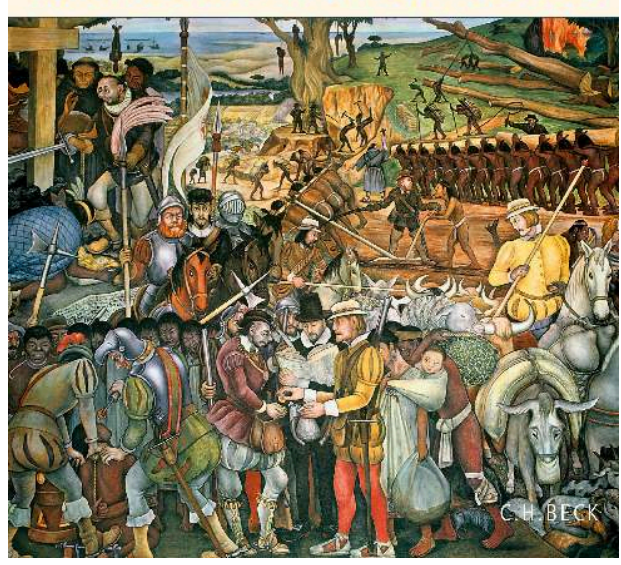
par une tendance à l'expansion. Le monde actuel est donc façonné par la «soumission du monde » opérée par l'Europe par la violence, depuis le $\mathrm{xv}^{\mathrm{e}}$ siècle et jusqu'au $\mathrm{xx}^{\mathrm{e}}$ siècle. En s'emparant de vastes territoires, l'Europe leur a aussi en grande partie fourni les idées et les moyens de se libérer aux $\mathrm{XIX}^{\mathrm{e}}$ et $\mathrm{XX}^{\mathrm{e}}$ siècles, même si cela s'avéra coûteux à court et à long terme. L'Europe a enfin largement induit l'occidentalisation, laquelle concourt, au Xxi ${ }^{\mathrm{e}}$ siècle, à la globalisation et aux migrations : l'expansion européenne se poursuit par une croissance économique qui fait fi des frontières. Avec un sens certain de la formule, W. Reinhard caractérise l'Europe à travers les siècles par la formule «je m'étends, donc je suis » (p. 17). En 24 chapitres chronologiques et régionaux, il nous brosse l'action de l'Europe - au-delà des termes trop étroits d'impérialisme et de colonialisme - dans le monde, en la reliant à la formation des États modernes en Europe et à des développements économiques. L'expansion européenne concerne encore la Russie mais non l'Empire ottoman; la formation des États-Unis d'Amérique est aussi considérée comme une "expansion secondaire ", et Israël est aussi inclus dans l'analyse en tant que colonie de peuplement. L'expansion en Europe comme à l'extérieur de l'Europe part d'abord d'empires, la structure politique lâche usuelle avant l'avènement de l'État souverain moderne aux $\mathrm{XVIII}^{\mathrm{e}}-\mathrm{XIX} \mathrm{X}^{\mathrm{e}}$ siècles, et prend la forme de vastes empires (Imperia), lesquels restent des empires au sens prémoderne, faiblement contrôlés. Aussi le terme de "colonie » n'apparaît-il qu'au XVIII ${ }^{\mathrm{e}}$ siècle. Même aux XIX ${ }^{\mathrm{e}}$ et $\mathrm{XX}^{\mathrm{e}}$ siècles, on ne peut guère parler d'État moderne que dans les colonies de peuplement britanniques et en Inde britannique. Le cas général est plutôt une domination par des clients indigènes, doublés d'une réserve européenne en cas de besoin. L'expansion est en général opérée par voie maritime, la Russie offrant le cas d'un empire formé par voie terrestre. Ce type d'empire continental s'avère difficile à décoloniser, surtout lorsque les populations locales sont remplacées par des colons et soit marginalisées, soit assimilées. Il ressort de ces considérations qu'un empire colonial consiste en la domination par la différence 
de développement économique, technique et militaire, entre les maîtres et les sujets. $\mathrm{Au}$ cours de l'histoire et à l'échelle de la planète, $\mathrm{W}$. Reinhard distingue trois types de colonies : 1) les bases établies à des fins économiques, commerciales ou militaires, 2) les colonies de peuplement, souvent instituées par le refoulement de populations nomades par des paysans sédentaires, 3) les colonies de domination fondées à des fins de contrôle mais sans peuplement systématique - les trois cas supposant des mouvements migratoires complexes et contraints, le recours à la force revenant à un aveu de faiblesse de la part des colonisateurs.

Si les motivations européennes sont peu surprenantes - des savoirs spécifiques, le zèle missionnaire, la volonté de profit commercial et de prestige, une politique de puissance - l'expansion se déroule de façon contingente, sans plan préétabli et sans grand soutien idéologique. Sur place, elle dépend de relations complexes, marquées par des interactions et des appropriations réciproques, et de la collaboration de certaines élites locales aux dépens des sujets. Sur le long terme, les colonies s'avèrent intéressantes d'un point de vue économique, même si les profits reviennent à des acteurs privés (p. 1263).

L'ouvrage de W. Reinhard s'impose par sa riche illustration (les cartes ne vont pas toujours de soi dans les ouvrages allemands), par l'ampleur de son information et la maîtrise d'un sujet particulièrement vaste et complexe. Il embrasse une perspective réellement globale et parvient à exceller tant sur l'époque moderne que sur les décolonisations $\mathrm{du} \mathrm{xx} \mathrm{x}^{\mathrm{e}}$ siècle. Le seul regret concerne les processus transculturels, qui auraient pu être plus creusés, des allusions peu explicitées à des polémiques historiennes, et la bibliographie certes polyglotte (allemand, anglais, français, espagnol, néerlandais) mais beaucoup trop serrée (aucun saut à la ligne) et découpée par chapitre, si bien qu'elle n'est guère utilisable. Très bien écrit, ce livre est un très grand ouvrage de référence, indispensable à toute étude globale en histoire moderne et contemporaine.

\section{INDEX}

Index chronologique : Période moderne, Époque contemporaine, Ouvrages transpériodiques Thèmes : Histoire des États et des pouvoirs, Manuels/Ouvrages généraux/Outils de travail

\section{AUTEURS}

\section{CLAIRE GANTET}

Université de Fribourg (Suisse)/Universität Freiburg (Schweiz) 